\title{
Características clínicas y demográficas en pacientes con cáncer de mama jóvenes de 35 años o menos, clínica Oncocare, 2004-2012
}

\author{
- Pedro Ramos
}

Oncocare.

Objetivo. Describir las características clínicas y demográficas de las pacientes con cáncer de mama jóvenes.

Métodos. Este estudio se realiza con la información de la clínica Oncocare en el período comprendido entre el $1^{\circ}$ de enero de 2004 hasta el 31 de mayo de 2012. Se incluyeron todas las pacientes con diagnóstico de cáncer de mama jóvenes con edad de 35 años o menos. Se efectuaron descripciones de las características clínicas y demográficas con estadística descriptiva.

Resultados. Veinticinco pacientes fueron identificadas en el estudio. La edad media fue de 30,7 años, el tiempo de seguimiento promedio fue de 50,6 meses, se presentaron 2 muertes para una frecuencia del $8 \%$ y 2 recaídas que corresponden a un total del $8 \%$.
La presentación clínica fue estadio avanzado en el $68 \%$, el estado ganglionar se distribuyó en ganglios positivos en el $57,88 \%$ de los casos. La mayoría de las pacientes pertenecen al régimen contributivo $(76 \%)$. Las pacientes recibieron quimioterapia neoadyuvante en el $64 \%$ y los esquemas más frecuentes fueron ACT en el $31,25 \%$ y $A C$ en el $62,5 \%$; la respuesta a la quimioterapia neoadyuvante fue: respuesta objetiva en un $81,25 \%$, respuesta completa en un $12,50 \%$, respuesta parcial en un $68,75 \%$. El receptor HER2 positivo en el $24 \%$, receptores estrógenos positivos en el $80 \%$ y progestágenos en el $64 \%$.

Conclusión. Las pacientes con cáncer de mama jóvenes son de alto riesgo de recaída y muerte, como se observa en esta serie de casos con un $8 \%$, lo cual coincide con lo reportado en la literatura.

\section{Análisis multivariado de los factores que inciden en la mortalidad en pacientes con cáncer de mama inicial (estadios I, IIA y IIB) en Colombia, clínica Oncocare, 2003-2012}

- Pedro Ramos

Oncocare.

Objetivo. Evaluar los factores pronósticos para mortalidad en pacientes adultos con cáncer de mama inicial.

Métodos. Análisis de información de la clínica Oncocare entre el $1^{\circ}$ de enero de 2003 hasta el 31 de julio de 2012. Se incluyeron todos los pacientes de 18 o más años con diagnóstico de cáncer de mama inicial (estadios I, IIA y IIB). Se construyeron curvas de supervivencia por el método de Kaplan-Meier, se compararon con el método de rangos logaritmos y se realizó un análisis de regresión de rangos proporcionales por Cox.

Resultados. Un total de 216 pacientes fueron identificados en el estudio. La tasa de mortalidad de la cohorte fue del $4,16 \%$ de pacientes y recaídas de un 5,56\%. La edad media fue de 55 años, la mediana de seguimiento fue 50,2 meses.

El estadio clínico se distribuyó en estadio I con el 21,76\%, IIA son un $35,65 \%$, IIB el $42,59 \%$. Los receptores de estrógenos son positivos en un $79,7 \%$, los de progestágeno son positivos en un $65,74 \%$ y los receptores de HER2 son positivos en un 17,13\%. Los pacientes recibieron quimioterapia neoadyuvante en un $32,87 \%$; el tipo de quimioterapia neoadyuvante fue $A C$ en el $46,48 \%$ y ACT en el $36,62 \%$. Recibieron quimioterapia adyuvante el $76,85 \%$, con AC un $50 \%$, ACTH un $19,88 \%$ y ACT un $13,25 \%$. La respuesta a la quimioterapia neoadyuvante fue: respuesta objetiva en un $73,34 \%$, respuesta completa en un $19,72 \%$, respuesta parcial en un $53,52 \%$. Se presentaron recaídas en un $5,56 \%$-locales $(2,31 \%)$, regionales $(0,46 \%)$ y sistémicas $(3,70 \%)$ - En el análisis multivariado, ninguno de los factores pronósticos, como el estadio clínico, el receptor hormonal (positivo), el receptor HER2 positivo y el grado histológico, fueron variable asociada a tiempos de supervivencia libre de enfermedad y global menores.

Conclusión. Los tiempos de supervivencia libre de enfermedad y global observados en la cohorte corresponden a los reportados en la literatura. 